Article Type: Original Article

'Going with the flow' of dementia: A reply to Nigel Rapport on the social ethics of care

\title{
Andrew Dawson
}

University of Melbourne

\section{Bryonny Goodwin-Hawkins}

Aberystwyth University

\section{Abstract}

In this brief editors' reply to Nigel Rapport's Afterword to the articles collected in the special issue 'Moralities of care in later life', we wonder: does the social ethics of care come with unacknowledged limits? We join with Rapport's call to maintain the individual's 'personal preserve' but observe-critically-that his "so far as possible, for as long as possible" makes for an uncomfortable caveat. To do so, we return ethnographically to the former mining town of Ashington, Northern England, and illustratively to a disease typically associated with the progressive loss of personhood: dementia. In contrast to both prevailing biomedical and person-centred views of dementia, we adopt a radically relational approach, which in practice calls for attentiveness and opening oneself up on the part of the carer to the individual life-world of another. Or, as it was for Ashington residents Eric and Elizabeth, a care-full inter-relationship re-found in 'going with the flow'.

Keywords: Nigel Rapport; care; ethics; dementia

This is the author manuscript accepted for publication and has undergone full peer review but has not been through the copyediting, typesetting, pagination and proofreading process, which may lead to differences between this version and the Version of Record. Please cite this article as doi: 10.1111/taja.12286

This article is protected by copyright. All rights reserved 


\section{INTRODUCTION}

Let us first offer our gratitude to Nigel Rapport for contributing an Afterword to this special issue. As ever, Rapport's reflections begin experience-near. He leads his readers deftly from the aches and cares of real lives to lessons as philosophical as they are anthropological. Readers, persuaded, may lean into agreement. But this is a Rapport thought-piece, of course, and there are bound to be individuals in there somewhere. If a 'post-cultural anthropology' (Rapport 2010) has detractors - and, of course, it does-it is among those who feel that we humans are always cultural beings, never quite tugged into completely individual selfhood.

Having already contributed an article to this volume that, while problematising a singular 'English' culture, nevertheless argues for particular industrial cultures of care, we might be expected to play the culture trump again. Rather, we want to push Rapport to the limits of his individual, for we note that there are limits in the social ethics of care. The trouble, as we see it, is that maintaining what Rapport calls the 'individual preserve' is not through the life-world unto death but until a need for care grows to such a degree that maintaining the individual preserve becomes 'impossible'.

Rapport, of course, draws no lines here, thick or thin, but we might pose that one of the conditions potentially able to push care to the brink is dementia, a progressive and terminal cognitive disease, often seen as chipping away at the individual. Such a loss may be fought, especially by family carers anxious to retrieve 'their' loved one. That is just what happened, at first, for Ashington residents Eric and Elizabeth. We turn now to their story, and to its conclusion in a relationality that might be an alternative addenda to the social ethics of care. We, like Eric, call it 'going with the flow'.

\section{DEMENTIA - EXPERIENCES}


Retired Ashingtoni teacher Elizabeth's cognitive decline seemed to come from nowhere. A short holiday in Paris with husband Eric ended with a snatched handbag on the Champs-Élysées. Then, almost as distressing, they were bundled into a seat-less police car for a rough ride to the gendarmerie to give their report. Afterwards, as Eric described, she went "all woozie". In hindsight, he thought that perhaps she had had a minor stroke.

Back home there followed a long period of depression, which Eric put down to Elizabeth being so shaken up. The antidepressants didn't help though. They “just drove her bonkers", Eric said. However, it was only at Christmas when he realised there was more to Elizabeth's state than her being merely "a bit down" or wrongly medicated. For the first time in more than fifty years of marriage she couldn't manage the roast. The turkey was hours underdone when the vegetables were ready. It "needed microwaving....I knew then that something serious was up." Such are the domestic ways in which an Ashington man might gauge the wellbeing of his wife.

Matters worsened dramatically from then onwards. Elizabeth became progressively incapable of doing everyday tasks like cooking, cleaning, and managing the bills and banks. Furthermore, for Eric, it was as though "my" Elizabeth was becoming a different person, and embarrassingly so. She became "potty-mouthed" (obscene), and started getting "all sexy with me", he explained. And, "she came over all religious. She hadn't been to chapel for years. She used to say she didn't need it anymore....that I was the answer to all her prayers," he laughed.

Eric reacted by implementing a care regime of tough love. Surely, he thought, the situation was fixable. He tried to stop Elizabeth "vegetating". Much less TV and, against her lifelong distaste for physical exercise, he forced her out on long walks. He also tried to reignite her equally lifelong love of the word-based board game Scrabble, “anything to stop her mind from continuing to fail.” Nothing worked though. And so, subsequently, Eric found himself falling into a decline of his own, borne less of 'carer burden' than of frustration and loss. 
A turning point and moment of acceptance came, however. Two things sparked it. He had held on to the hope that she did not have some kind of degenerative brain disorder, because the doctors hadn't diagnosed one. However, his older and wiser sister Miriam explained why: "The moment they say it's Alzheimer's is the moment that they have to provide Alzheimer's care." A political economy of diagnosis "under the Tories ${ }^{\mathrm{ii}}$ " she went on. But more impacting than this was the confusion and fear that Eric saw in Elizabeth's face when she walked from one room to another in their family home. So diminished was her memory that she could barely recall instantly the things that had been familiar throughout her life. The only exception to this was Eric himself, upon whom she became almost solely reliant, especially for any sense of security and wellbeing.

At this point Eric realised that there was no point in trying to recuperate 'his' Elizabeth. He started to just "go with the flow", and "enter Lizzie's world", as he described it. He even started to get sexy in return, "not in a carnal way you understand, but flirting, holding hands and such....like when we were kids." Furthermore, accompanying her to chapel, the God he had abandoned and who he felt had abandoned him when his beloved nephew committed suicide many years before, came back into his life.

The final years with Elizabeth were hard work for Eric,. However, as he opened himself to her altering being, perhaps to an extent that he had never done before, they were often, unexpectedly, fun times and always times suffused with feelings of solace and love. After an unexpected and short illness Elizabeth contracted pneumonia and died. Eric says that no matter how trying the final years of her life had been he would do anything in the world to have "Dizzy Miss Lizzie", as he had affectionately come to call her, back.

\section{DEMENTIA - APPROACHES}


Understanding of dementias and their related regimes of care have undergone several transformations. Initially seen as a normal outcome of ageing minds to be managed within the home or asylum, they came to be seen as 'problems' of the body that, as such, fell within the purview of biomedicine (Andrews 2017). In the 1970 s a key critique of biomedicine in general and its approach to dementia in particular emerged, highlighting biomedicine's exclusion of the centrality of the patient's experience as an outcome of a narrow focus on diagnosis, treatment and the forlorn hope of cure (Kleinman 2015). This led to the emergence of calls for person-centred approaches that aimed to treat biomedicine's 'sufferer' as both an individual and a social being, and, above all a person to be valued (Kitwood 1997).

Despite such explicit differences, biomedicine and person-centred care do share much in common. In particular, as Macdonald describes, both treat dementia as 'death in life or life in death' (2018). The sufferer is rendered as a living dead by virtue of her capacity to confound biomedicine's raison d'etre of the cure, or, in the case of person-centred approaches, as a person paradoxically defined by progressive and inexorable loss of personhood.

What concerns us here is how these approaches render individuality. Biomedicine, according to Moser, "shapes life with dementia as a more or less given disease trajectory in which the subjective and agential 'I' of the patient is progressively broken down and eradicated" (2011: 715). Conversely, Macdonald scathingly describes person-centred approaches in practice thus: "designed to counter the erasure of the person, 'recognizing the person' is being turned into a 'technique' of care, part of a carer toolkit, something to record on a patient's file their personal history, the name of their husband or dog, ways to deal with agitation" (2018: 294). In short, in both biomedicine and, even person-centred approaches the individual is eviscerated.

In recent years a significant alternative, often termed the relational approach to dementia and dementia care, has emerged. Its central premise is that to be human is to be social: a relational being (Macdonald 2018). It is characterised, 
obviously, by the endeavour to hold the person with dementia in social connection. For that connection to happen requires a skilled attentiveness on the part of the carer to the highly individual and altering life-world of another.

For example, Moser describes how the screams of some people with dementia are medically rendered as pathological symptoms associated with a particular stage in disease development. Their manifestation leads, invariably, to carer strategies of control and isolation of the 'patient', as though there is nothing else that can be done. Yet, for Moser and some carers, such screams represent a form of bodily communication, which, unlike the ability to communicate verbally, does not diminish but gains greater salience. A relational approach then, might involve carer attentiveness to the highly individuated non-verbal modes of communication upon which specific people with dementia come to rely-such as touch and eye contact-in order to facilitate their remaining in connection.

\section{GOING WITH THE FLOW AND RAPPORT'S SOCIAL ETHICS OF CARE}

In his Afterword to this special issue Nigel Rapport develops a social ethics of care. It is founded substantially on the work of Emmanuel Levinas, for whom the other is inexorably 'alter' or, as Rapport paraphrases, "possessed of a dimension of seperatedness whose interiority and secrecy ego can never overcome". Not wishing to rehearse Rapport's article in its full and convincing complexity, he argues, basically, that social ethics of care must be founded upon recognition, respect and, crucially, preservation of/for an individual's 'personal preserve'. For Rapport, care in practice needs to consist of a balance between behaviours of 'inclusion' (empathy and the like) and, 'autonomy', that is, seeking to maintain the personal preserve.

At first blush Rapport's ideas might not appear to sit easily with the kind of relational approach to dementia care outlined above. We assume that for Rapport a carer assuming attentiveness to the highly individual and altering lifeworld of a person with dementia might constitute the beginnings of a slippery 
slope to colonisation of that life-world. Yet, there are different modes of attentiveness. There is an attentiveness directed at coming and claiming to 'know' fully the other which, following Rapport, is both erroneous and a form of violence to the other's personal preserve. Contrastingly, there is an attentiveness of the kind that Eric articulates, of 'going with the flow', a launching oneself into the life-world of an other without ever presuming to know fully what that lifeworld is. For Eric this involved getting 'sexy' and getting religious with Elizabeth. And, we would argue, going with the flow is a supreme act of respect for the personal preserve-an ethical stance that we share with Rapport-for it instantiates that respect in an active social relation.

One might baulk at 'going with the flow' as an appropriate means of care in relation to dementia-and Rapport might do too. Echoing the limits that liberal scholars traditionally place upon their insistences, Rapport states of his social ethics of care: "For the elderly it means caring that their autonomy is not infringed: that so far as possible, and for as long as possible, the elderly individual maintains not only his or her abiding authorship of his or her lifeproject(s) but also authority, determining the course of that life and the trajectory of its becoming." So far as possible, and for as long as possible-but 'possible' here evidently stops eventually. The trouble for Rapport's ethics of care is: who is to say when that stop has arrived?

We would argue that a social ethics of care of the kind that Rapport articulates, that insists upon the protection of the personal reserve, should always pertain, including for those with perceived diminished capacity. And, we argue, that a key means of ethical enactment within care relationships is 'going with the flow': joining into the life-world of an other without ever presuming to fully know what that life-world is. More than a moral stance, this is a guide for practice, mutually beneficial for the carer and cared for. As Eric found when, instead of trying to remake the Elizabeth that he had formerly known he gave in to entering "Lizzie's world", both he and she found a happiness that her illness had previously threatened to deny them both. 
Please send correspondence to Andrew Dawson: dawsona@unimelb.edu.au

\section{REFERENCES}

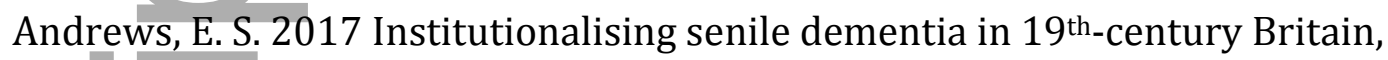
Sociology of Health and Illness 39(2): 244-57.

Kitwood, T.1997 Dementia reconsidered: The person comes first. Milton Keynes: Open University.

Kleinman, A. From illness as culture to caregiving as moral experience, $\mathrm{NeW}$ England Journal of Medicine 368(15): 1376-77.

Macdonald, G. 2018 Death in life or life in death? Dementia's ontological challenge, in Life's End: Ethnographic Perspectives, A. Dawson and B. Goodwin-Hawkins (eds) Death Studies, 42(5): 290-97.

Moser, I. 2011 Dementia and the limits of life: Anthropological sensibilities: STS interferences, and possibilities for action in care, Science, Technology and Human Values 36(5): 704-22.

Rapport, N. 2010 'Apprehending Anyone: The non-indexical, post-cultural and cosmopolitan human actor', Journal of the Royal Anthropological Institute (N.S.) 16(1): 84-101.

\section{NOTES}

i The town in northern England where Dawson conducts his research.

ii A name given to the, then governing Conservative Party. 


\section{University Library}

\section{- M M I N E R VA A gateway to Melbourne's research publications}

Minerva Access is the Institutional Repository of The University of Melbourne

Author/s:

Dawson, A;Goodwin-Hawkins, B

Title:

"Going with the flow' of dementia: A reply to Nigel Rapport on the social ethics of care

Date:

2018-08-01

Citation:

Dawson, A. \& Goodwin-Hawkins, B. (2018). "Going with the flow' of dementia: A reply to Nigel Rapport on the social ethics of care. AUSTRALIAN JOURNAL OF ANTHROPOLOGY, 29 (2), pp.258-262. https://doi.org/10.1111/taja.12286.

Persistent Link:

http://hdl.handle.net/11343/284162 